\title{
Sources of Stress Among Undergraduate Nursing Students
}

\author{
Salmah Alghamdi ${ }^{1}$, Shrooq Aljabri ${ }^{2}$, Ghayda Jafari ${ }^{2}$, Rawan Alzebali ${ }^{2}$, Nada Alkunaidiri ${ }^{2}$ \& Nada Kalantan ${ }^{2}$ \\ ${ }^{1} \mathrm{PhD}$, Assistant professor, Faculty of Nursing, King Abdulaziz University, Jeddah, Saudi Arabia \\ ${ }^{2}$ BSN, Registered Nurse, Faculty of Nursing, King Abdulaziz University, Jeddah, Saudi Arabia \\ Correspondence: Dr. Salmah Alghamdi, Faculty of Nursing. King Abdulaziz University. Jeddah, Saudi Arabia. \\ E-mail: saalghamdi6@kau.edu.sa
}

Received: June 3, 2019 Accepted: July 11, 2019 Online Published: July 22, 2019

doi:10.5539/gjhs.v11n9p116 URL: https://doi.org/10.5539/gjhs.v11n9p116

\begin{abstract}
Objective: Stress is common among nursing students during their first years of study. Nursing students often experience high levels of stress because they frequently encounter various challenges that can negatively affect their academic performance and general health. However, common sources of stress among undergraduate nursing students have not been well identified. Therefore, the purpose of this study was to identify the common sources of stress among undergraduate nursing students.
\end{abstract}

Methods: This was a descriptive, cross-sectional study. The convenience sample included 87 female nursing students. The Student Nurse Stress Index (SNSI) was used to describe the sources of stress from four domains: academic load, clinical concerns, personal problems, and interface worries.

Results: The majority (95.4\%) of the participants were aged between 19-21 years. The major source of stress was academic load $(\mathrm{M}=3.38, \mathrm{SD}=0.82)$, followed by interface worries $(\mathrm{M}=3.22, \mathrm{SD}=0.79)$, clinical concerns $(\mathrm{M}=$ $2.80, \mathrm{SD}=0.78)$, and personal problems $(\mathrm{M}=2.43, \mathrm{SD}=1.02)$.

Conclusion: The nursing students' stress resulting from their academic load was higher than the other sources of stress, and it was related to the large number of materials, assignments, or subjects required for nursing students. It is recommended that undergraduate nursing students are supported by having schools organize the amount of academic work required for each subject. Given that the students' academic load was the most common source of stress, coordination between the students and faculty about the requirements of each course is warranted.

Keywords: stress, undergraduate, nursing; students, academic load

\section{Introduction}

Stress is a reaction to any challenging event that requires an individual to react or adapt via a physical, emotional, mental and psychological responses. The capability of the individuals to adapt and the availability of helpful resources are important to overcome stressful situations. Maladaptive responses, or negative, unhealthy responses, could lead to serious health problems, such as anxiety, depression, and other mental health disorders (Townsend, 2015), that could interfere with students ability to learn. Undergraduate students can experience stress during their study in different disciplines. Nursing is a one of health disciplines that could be challenging and stressful for undergraduate students (Sossah \& Asiedu, 2015).

Nursing students are subject to several stressors, including challenging course subjects, extended study periods, the anxiety of clinical training, and the need for critical thinking. Overcoming these stressors requires emotional and personal maturity (Al-barrak et al., 2011; Sossah \& Asiedu, 2015). Additional stressors include extensive assignments, weakness in English, and the fear of failing exams (Hirsch, Barlem, Tomaschewski-Barlem, Lunardi, \& Oliveira, 2015).

Furthermore, nursing students also face the stress of beginning clinical training. Especially as they start their clinical practice, the fear of hurting or harming patients may affect their practice. They are also frequently concerned about not getting along with other staff members or patients, possible deficiencies in their professional training, fear of encountering unfamiliar cases, and anxiety about their uncertain future (Hirsch et al., 2015).

Personal stress (such as anxiety caused by students' uncertain future), social stress, and interface worries (the poor public image of nursing in Saudi Arabia is considered as a social stressor for nursing students) are common for nursing students, and students may also experience other sources of stress, such as family issues and physical 
problems (Hirsch et al., 2015).

In addition, nursing students also could encounter intrapersonal stress resulting from financial burdens or/and interpersonal relationships with classmates. These stressors may come from positive life changes, such as marriage, graduation, or starting a new job, or from negative life changes, such as losing a job, divorcing, or losing a family member. All these stressors could negatively affect students' academic performance (Al-barrak et al., 2011).

According to Aedh, Elfaki, and Mohamed (2015), nursing students experience numerous challenges in clinical environments that could lead to perceived stress, such as the technique of using medical equipment, effective interaction with colleagues, and managing unstable cases. In addition, nursing students navigate unexpected or challenging situations, especially when assisting patients' relatives, who are often upset regarding their loved ones' diagnoses.

The main two sources of stress reported by Saudi Arabian nursing students were: alterations in sleeping behaviors and eating behaviors (Al-barrak et al., 2011). Moreover, the inability to improve patients' conditions was mentioned by $12.7 \%$ of students, and the inability to answer questions asked by patients or their families was mentioned by $10.6 \%$ of students (Al-barrak et al., 2011). In addition, the study found that students who live on campus ( $26.5 \%$ of students in the mentioned study) might suffer from higher stress levels than students who live in off-campus housing (Al-barrak et al., 2011).

The last domain (interface worries) was defined as the students' nonspecific worries of being in nursing school (Jones \& Johnston, 1999). Interface worries mainly focus on stress that may occur due to the pressure students encounter when communicating and interacting with new people in their college and home environments (Shukla, Kalra, \& Pakhare, 2012). Al-barrak et al. (2011) found that changes in social life were counted as sources of students' interface worries (i.e., stress). A study completed by Mahfouz and Alsahli (2016) revealed that students who live far away from their universities experience more stress than students who live closer to their places of study. This could be due to the extra time required to commute to classes. Additionally, even students living with their parents may suffer from high stress levels if they argue with their parents or experience other types of family stress (Mahfouz \& Alsahli, 2016). Other studies have found that stress is related to an imbalance between home and work, which creates a feeling of unpreparedness (Chernomas \& Shapiro, 2013).

Uncontrolled stressors could lead to sleep disorders, a decreased ability to concentrate, depression, and emotional disturbances, which can negatively affect the academic performance of nursing students (Niknami, Dehghani, Bouraki, Kazemnejad, \& Soleimani, 2015). Moreover, dropout issue continues to appear in nursing colleges (S. Mahran, A. Mahran, \& Al Nagshabandi, 2012). However, most of studies that assessed the sources of stress were in Western countries which have different social backgrounds (Eswi, Radi, \& Youssri, 2013). Very few studies have assessed stress among undergraduate nursing students in Saudi Arabia. Therefore, the purpose of this study was to identify the sources of stress as perceived by nursing students.

\section{Methods}

\subsection{Research Design}

This study utilized a descriptive, cross-sectional design.

\subsection{Sampling}

A convenience sample of Saudi female second-year nursing students at King Abdulaziz University, the faculty of Nursing, was gathered. Inclusion criteria included full-time nursing students, aged 18-25, and enrolled in public universities. Exclusion criteria included part-time students or students attending private universities.

\subsection{Sample Size}

$\mathrm{G}^{*}$ Power was used to estimate the required sample size (Faul, Erdfelder, Buchner, \& Lang, 2009). A priori analysis was executed to compute the sample size for one sample means. The input parameters of an alpha of 0.05 , a power of 0.80 , and a medium effect size of 0.5 revealed a recommended sample size of 27 .

\subsection{Data-Collection Tools}

The study questionnaire contains two parts. The first part contains the sociodemographic characteristics questionnaire (age, nationality, marital status, city status, housing status, family income, health problems, any relatives who are nurses, internet and computer access, and English language status). The second part includes the Student Nurse Stress Index (SNSI), which is five points, Likert-type scale (Jones \& Johnston, 1999). It contains four factors: personal problems, clinical concerns, academic load, and interface worries. The SNSI contains total of 22 items, and each item is scored from one to five; a score of one means the item is not stressful, while a score of 
five means the item is extremely stressful. The reliability of the SNSI in this study was 0.84 .

\subsection{Procedure}

The researchers obtained permission from the authors to use the SNSI tool. The ethical approval was obtained from the Faculty of Nursing, King Abdulaziz University prior to collecting the data. An electronic questionnaire containing the consent form was created using Google forms. The study was explained to the participants, and a link to the consent form and the questionnaire was sent to the students via their smartphones. The questionnaire took the participants approximately five minutes to complete.

\subsection{Data Analysis}

Statistical analysis was performed by using SPSS programs. The data were entered and cleaned. Study variables were analyzed using descriptive statistics, including means, standard deviations, and frequency (percentage) to describe continuous and categorical variables, respectively.

\section{Results}

Overall, 87 students participated in the study, and the results are presented in two parts. The first part includes sociodemographic characteristics and other environmental and personal variables that interfere with the most common stressors that are experienced by students, and the second part includes the SNSI.

\subsection{Sociodemographic Characteristics}

The majority of the participants (95.4\%) were single and aged between 19-21 years. Most of them (87.2\%) were Saudi (97.7\%), living in Jeddah (89.5\%), and living with their parents. More than half of the participants (51.7\%) reported a monthly income of 7000 Saudi Arabian Riyal (SAR) or above. The socio-demographic characteristics are displayed in Table 1. Regarding other environmental and personal variables, $52.3 \%$ of the participants had a family member or a friend in the nursing profession. A majority of students reported the availability of internet and computer access (95.4\%), no difficulties with the English language (74.7\%), and no health problems $(86.2 \%)$.

Table 1. Socio-demographic characteristics of studied subjects $(\mathrm{N}=87)$

\begin{tabular}{lcc}
\hline Socio-demographic characteristics & Frequency & Percentage \\
\hline Age: & 2 & $2.3 \%$ \\
Less than 18 & 83 & $95.4 \%$ \\
$19-21$ & 2 & $2.3 \%$ \\
$22-24$ & & \\
\hline Nationality: & 85 & $97.7 \%$ \\
Saudi & 2 & $2.3 \%$ \\
None Saudi & & \\
\hline Marital status: & 85 & $98.8 \%$ \\
Single & 1 & $1.2 \%$ \\
Married & & $89.5 \%$ \\
\hline City: & 77 & $10.5 \%$ \\
Jeddah & 9 & $89.7 \%$ \\
Outside Jeddah & & $10.3 \%$ \\
\hline Living with family: & 78 & \\
Yes & 9 & $87.2 \%$ \\
No & 75 & $12.8 \%$ \\
\hline Living with parents: & 11 & \\
Yes & & \\
No & & \\
\hline
\end{tabular}


Monthly income:

$\begin{array}{lcr}3000 \text { SAR or Less } & 10 & 11.5 \% \\ 4000 \text { SAR- } 7000 \text { SAR } & 8 & 9.2 \% \\ 7000 \text { SAR and above } & 45 & 51.7 \% \\ \text { Don't know } & 24 & 27.5 \%\end{array}$

\subsection{Source of Stress Among Nursing Student}

Each participant (87 in total) reported that her major source of stress was academic load $(\mathrm{M}=3.38, \mathrm{SD}=0.83$ ). The means of the categories of the SNSI are shown in Figure 1. The highest mean for the items included under academic load was the amount of classwork material to be learned, and examination and/or grades $(\mathrm{M}=3.77, \mathrm{SD}$ $=1.24)$. The second source of stress reported by the students was interface worries $(\mathrm{M}=3.22, \mathrm{SD}=0.79)$. The highest mean for the items included under interface worries was a lack of free time $(\mathrm{M}=3.76, \mathrm{SD}=1.35)$. The third source of stress was clinical concerns $(\mathrm{M}=2.80, \mathrm{SD}=0.78)$, and the fourth source of stress was personal problems $(\mathrm{M}=2.43, \mathrm{SD}=1.02)$. The means and standard deviations of the 22-item of SNSI are presented in Table 2.

Table 2. Stress Nursing Student Index (SNSI) mean and stander deviation

\begin{tabular}{|c|c|c|}
\hline Categories & Mean & Std. Deviation \\
\hline Academic load & 3.38 & 0.82 \\
\hline Amount of classwork material to be learned & 3.77 & 1.24 \\
\hline Difficulty of classwork material to be learned & 3.13 & 1.17 \\
\hline Examination and/or grades & 3.77 & 1.12 \\
\hline Fear of failing in course & 3.40 & 1.47 \\
\hline Atmosphere created by teaching staff & 2.79 & 1.15 \\
\hline Clinical concerns & 2.80 & 0.78 \\
\hline Relations with other professionals & 2.59 & 1.25 \\
\hline Too much responsibility & 3.41 & 1.25 \\
\hline Client attitudes towards me & 2.64 & 1.11 \\
\hline Client attitudes towards my profession & 2.60 & 1.14 \\
\hline Relations with staff in the clinical area & 2.83 & 1.20 \\
\hline I am not sure what is expected of me & 2.85 & 1.30 \\
\hline Personal problems & 2.43 & 1.02 \\
\hline Actual personal health problems & 2.23 & 1.34 \\
\hline Physical health of other family members & 2.51 & 1.40 \\
\hline Relationships with parents & 2.55 & 1.47 \\
\hline Other personal problems & 2.53 & 1.39 \\
\hline Interface worries & 3.22 & 0.79 \\
\hline Peer competition & 2.67 & 1.26 \\
\hline Attitudes/expectations of other professionals towards nursing. & 2.78 & 1.07 \\
\hline Lack of free time & 3.76 & 1.35 \\
\hline College/School response to student needs & 3.15 & 1.31 \\
\hline Lack of timely feedback about performance & 2.99 & 1.26 \\
\hline limited entertainment time & 3.56 & 1.26 \\
\hline limited family time & 3.64 & 1.28 \\
\hline
\end{tabular}


In this study, there were significant relationships between academic load and monthly income $(\mathrm{R}=-.320, P \leq 0.05)$, and personal problems and monthly income $(\mathrm{R}=-.360, P \leq 0.05)$. However, there were no significant relationships between clinical concerns, interface worries, and monthly income. See Table 3 for detailed information about the correlations among study variables.

Table 3. Relationship between the Stress Nursing Student Index (SNSI) and monthly income

\begin{tabular}{lll}
\hline \multirow{2}{*}{ Variables } & \multicolumn{2}{l}{ Monthly Income } \\
\cline { 2 - 3 } & $R$ & $p$-value \\
\hline Academic load & $-.320-*$ & .002 \\
Clinical concerns & $-.183-$ & .049 \\
Personal problems & $-.360-*$ & .000 \\
Interface worries & $-.218-^{*}$ & .024 \\
\hline
\end{tabular}

*Correlation is significant at the p-value $<0.05$.

\section{Discussion}

Nursing students frequently experience several sources of stressors, which can have undesirable effects on their academic performance and emotional and physical health. Coping with various stressful situations can occur during the years of nursing study (Al-barrak et al., 2011). Nursing students' stress could be due to their academic load, clinical concerns, personal problems, and interface worries. Therefore, the purpose of this study was to identify the sources of stress among nursing students at the Faculty of Nursing, King Abdulaziz University. The findings revealed that the major source of stress among second-year nursing students was academic load $(\mathrm{M}=$ $3.38)$, followed by interface worries $(M=3.2)$, clinical concerns $(M=2.80)$, and personal problems $(M=2.43)$.

Related to study subjects and according to the means of the SNSI categories, academic load was the highest source of stress among nursing students because nursing students are learning about new subjects while trying to adjust to academic setting. Thus, the students reported that the amount of classwork and their grades/examinations are the highest source of stress $(M=3.77)$, followed by a fear of failing a course $(M=3.40)$. The atmosphere created by teaching staff was considered the lowest source of stress $(M=2.79)$. In this domain, there was a significant negative relationship between academic load and monthly income $(\mathrm{R}=-.320, P \leq 0.05)$. As students' monthly income increases, their academic load stressor decreases. Students with a low socioeconomic status suffer from the academic load stressor more than students with a high socioeconomic status. Such results can be attributed to the accessibility of required medical equipment, academic textbooks, and computers.

In congruence with the above findings, Al-barrak et al. (2011) found that more than half of students (64.9\%) reported that academic workload was the most frequent source of stress, which means that the content taught in nursing classes could be far from the students' expectations of college coursework. The study completed by Eswi et al. (2013) found that academic stressors had the highest contribution to causing stress among undergraduate Saudi nursing students. Eswi et al. (2013) revealed that 57\% of students reported having several responsibilities as the top reported stressor, while $43.0 \%$ stated academic stressors, such as lower grades and multiple assignments required. In addition, students reported many challenges at the same time and not enough free time as sources of stress (Eswi et al., 2013).

Interface worries were the second most reported source of stress; this could be because second-year nursing students face new experiences as they settle into their nursing major and need time to adapt to the major changes that interfere with their academic and personal lives. The seven items in this category have varying means, reported as follows: a lack of free time $(\mathrm{M}=3.76)$, not enough family time $(\mathrm{M}=3.64)$, limited entertainment time $(\mathrm{M}=3.56)$, and school responses to students' needs $(\mathrm{M}=3.15)$. The less frequently reported sources of stress were: a lack of timely feedback $(\mathrm{M}=2.99)$, attitudes of other professions toward nurses $(\mathrm{M}=2.78)$, and peer competition $(\mathrm{M}=2.67)$. A nurse's ability to achieve an optimal balance between her career and her personal life will decrease the risk of interface worries (Clark \& Pelicci, 2011).

Clinical concerns were the third most frequent source of stress $(\mathrm{M}=2.80)$, and this could be because student nurses are practicing clinical training for the first time, which can be an intense, pressure-filled experience. The most frequently mentioned stressor was feeling as if they have too many responsibilities $(\mathrm{M}=3.41)$. In addition, students might feel as if they are unsure what is expected of them $(\mathrm{M}=2.85)$, encounter stressful 
attitudes/expectations of other professionals toward nursing $(\mathrm{M}=2.59)$, and fear encountering harmful patient-related situations $(\mathrm{M}=2.64)$.

The findings from the current study are congruent with results from the study completed by Al-Gamal, Alhosain, and Alsunaye (2017), which focused on stressors and coping strategies among Saudi Aarbian nursing students during clinical practice. In the study completed by Al-Gamal et al. (2017), the most reported stressors among students were stress from instructors and stress from nursing staff. Nursing students also reported stress from providing patient care, stress from assignments, and stress from their workload. The study completed by Al Zayyat and Al-Gamal (2014) is in agreement with the findings found by Al-Gamal et al. (2017); the researchers found that the most common stressors for nursing students in Jordan were related to providing patient care, workload, completing assignments, and interacting with teachers and nursing staff.

In the current study, personal factors, such as health and family, were considered as a major part of students' lives because personal problems that can distract students and interfere with their academic performance could be perceived as stressors.

Therefore, personal problems were the fourth most reported source of stress $(M=2.42)$ on the SNSI. The highest items were relationships with parents $(\mathrm{M}=2.55)$, other personal problems $(\mathrm{M}=2.53)$, and the physical health of other family members $(\mathrm{M}=2.51)$. The least reported item was actual personal health problems $(\mathrm{M}=2.23)$. In this domain, a significant reverse (negative) relationship appeared between personal problems and monthly income ( $\mathrm{R}$ $=-.360, P \leq 0.05)$. As students' monthly income increases, their personal problems stressor will decrease, gradually. Students with a low socioeconomic status suffer from personal stressors more than students with a high socioeconomic status because health problems in families with a low socioeconomic status can financially devastate such families via paying for treatments and medical intervention. This financial strain can interfere with the home environment and relationships between family members, leading to increased stress among students.

A study completed in Pakistan by Parveen and Inayat (2017) found that the most common source of stress among nursing students was getting lower grades than anticipated (84.6\%). Of the surveyed students, $70 \%$ strongly agreed or agreed that they have difficulty balancing their time between studying and resting, and $84 \%$ of students strongly agreed or agreed that career opportunities and their uncertain future cause stress (Parveen \& Inayat, 2017).

According to Al-barrak et al. (2011), 29.9\% of nursing students have stress related to declines in personal health, while $19.8 \%$ reported that major family events (death/illness) were a source of stress for them. In addition, $16.7 \%$ of nursing students considered fighting with family members as a stressor.

The limitations of this study include the study's descriptive design, which means causal relationships could not be established; the use of a convenience sample within one college at one university, which could limit the generalizability of the results.

\section{Conclusion}

The purpose of this study was to identify the sources of stress among second-year nursing students, by using the SNSI scale. The results showed that the students suffered from the academic load stressor more frequently than other stressors related to nursing course content and examinations. Interface worries were the second most reported category; when students encounter interfaces worries, they begin to withdrawal from their social lives due to a lack of free time. The clinical category was the third most reported source of stress, and it is experienced when students are exposed to new responsibilities in their clinical training. Finally, there were a few students who mentioned the personal problem category as a source of stress. The outcomes from this study will help researchers, professors, and students understand the sources of stress and develop further management strategies to reduce these stressors.

\section{Recommendation and Implications}

It is important to understand how stressors can affect students' performance and how they can affect students' ability to continue studying nursing. Therefore, future studies can expand these findings through more detailed interviews or qualitative studies, and train students about stress-management techniques to cope with unexpected events in their clinical practice. College staff should maintain a stable academic environment to help students achieve optimal learning outcomes. College staff should focus on the students' personal needs and offer an orientation program before the students begin nursing courses in order to reduce the sources of stress during the students' first year. In addition, given that academic load was the most reported source of stress, future studies could examine intervention programs intended to reduce the academic load among junior nursing students.

\section{Competing Interests Statement}

The authors declare that there are no competing or potential conflicts of interest. 


\section{References}

Aedh, A., Elfaki, N., \& Mohamed, I. (2015). Factors associated with stress among nursing students (Najran University - Saudi Arabia). IOSR Journal of Nursing and Health Science, 4, 33-38.

Al-barrak, M., El-nady, M. T., \& Fayad, E. A. (2011). Sources of stress as perceived by nursing students at King Saud University. Medical Journal of Cairo University, 79, 541-553.

Al-Gamal, E., Alhosain, A., \& Alsunaye, K. (2017). Stress and coping strategies among Saudi nursing students during clinical education. Perspectives in Psychiatric Care, 54, 198-205. https://doi.org/10.1111/ppc.12223

Al-Zayyat, A., \& Al-Gamal, E. (2014). Perceived stress and coping strategies among Jordanian nursing students during clinical practice in psychiatric/mental health course. International Journal of Mental Health Nursing, 23(4), 326-335. https://doi.org/10.1111/inm. 12054

Chernomas, W. M., \& Shapiro, C. (2013). Stress, depression, and anxiety among undergraduate nursing students. International Journal of Nursing Education Scholarship, 10, 255-266. https://doi.org/10.1515/ijnes-2012-0032

Clark, C., \& Pelicci, G. (2011). An integral nursing education: A stress management and life balance course. International Journal for Human Caring, 15, 13-22. https://doi.org/10.20467/1091-5710.15.1.13

Crown, D. P., \& Marlowe, D. A. (1960). A new scale of social desirability independent of psychopathology. Journal of Consulting Psychology, 24, 349-354. https://doi.org/10.1037/h0047358

Eswi, A. S., Radi, S., \& Youssri, H. (2013). Stress/stressors as perceived by baccalaureate Saudi nursing students. Middle-East Journal of Scientific Research, 14, 193-202.

Faul, F., Erdfelder, E., Buchner, A., \& Lang, A. G. (2009). Statistical power analyses using G*Power 3.1: Tests for correlation and regression analyses. Behavior Research Methods, 41(4), 1149-1160. https://doi.org/10.3758/BRM.41.4.1149

Hirsch, C. D., Barlem, E. L., Tomaschewski-Barlem, J. G., Lunardi, V. L., \& Oliveira, A. C. (2015). Predictors of stress and coping strategies adopted by nursing students. Acta Paul Enferm, 28, 224-229. https://doi.org/10.1590/1982-0194201500038

Jones, M. C., \& Johnston, D. W. (1999). The derivation of a brief Student Nurse Stress Index. Work \& Stress Journal, 13, 162-181. https://doi.org/10.1080/026783799296129

Mahfouz, R., \& Alsahli, H. (2016). Perceived stress and coping strategies among newly nurse students in clinical practice. Journal of Education and Practice, 7, 1735-2222.

Mahran, S. M., Mahran, A., \& Al Nagshabandi, E. (2012). Impact of perceived public image on turnover intention of female students from joining the nursing profession at King Abdulaziz University, Kingdom of Saudi Arabia. IOSR Journal of Nursing and Health Science, 1, 19-28. https://doi.org/10.9790/1959-0111928

Niknami, M., Dehghani, F., Bouraki, S., Kazemnejad, K., \& Soleimani, R. (2015). An assessment of the stressors and ways of coping in Iranian medical sciences students. Iranian Journal of Nursing and Midwifery Research, 20, 521-525. https://doi.org/10.4103/1735-9066.161009

Parveen, A., \& Inayat, S. (2017). Evaluation of factors of stress among nursing students. Journal of Advanced Practices in Nursing, 2(2), 136-140.

Shukla, A., Kalra, G., \& Pakhare, A. (2012). Understanding stress and coping mechanisms in Indian student nurses. Sri Lanka Journal of Psychiatry, 4(2), 29-33. https://doi.org/10.4038/sljpsyc.v4i2.5387

Sossah, L., \& Asiedu, Y. (2015). Stress management and resilience in junior and senior nursing students in Ghana. European Journal of Research and Reflection in Educational Sciences, 3, 46-53.

Townsend, M. C. (2015). Psychiatric mental health nursing: Concepts of care in evidence-based practice. Philadelphia, PA: F. A. Davis Company.

\section{Copyrights}

Copyright for this article is retained by the author(s), with first publication rights granted to the journal.

This is an open-access article distributed under the terms and conditions of the Creative Commons Attribution license (http://creativecommons.org/licenses/by/4.0/). 